\title{
Cine y Pediatría (I): una oportunidad para la docencia y la humanización en nuestra práctica clínica
}

\author{
J. González de Dios \\ Servicio de Pediatría. Hospital General Universitario de Alicante. Departamento de Pediatría. \\ Universidad Miguel Hernández. Alicante. España.
}

El cine y la orientación de la educación médica desde la estética

"Erase una vez, un elegante bulevar de la ciudad de París...". Así podemos empezar una de las fábulas más maraviIlosas: el nacimiento del cine. El fenómeno cinematográfico, tal como lo conocemos, nació con la exhibición comercial el 28 de diciembre de 1895 en París, en el Grand Café del Boulevard des Capucines. Allí los inventores Louis y Auguste Lumiére proyectaron varios documentales. La primera película oficial fue La sortie de I'usine Lumiére a Lyon. Pero en aquella primera sesión se proyectaron varios documentales más, entre ellos Llegada de un tren, Estanque de las Tullerías, La partida de cartas o El desayuno del bebé... Desde sus inicios se confirma que la infancia se convierte en un motivo de inspiración para el cinematógrafo, manifestación artística basada en el movimiento de las imágenes (sus raíces griegas lo avalan: kiné y grafos).

La infancia ha sido, es y será motivo de inspiración y reflexión en el arte, en cualquiera de sus manifestaciones, bien sea el cine (denominado "séptimo arte"), como en cualquiera de las previas seis Bellas Artes consideradas del mundo clásico: arquitectura, escultura, pintura, música (incluye el teatro), declamación (incluye la poesía) y danza. Niños y adolescentes comparten la aventura e historia del cine, bien en papeles principales o de reparto, como núcleo o como excusa argumental, en la salud y en la enfermedad.

La visión que el cine proporciona a la infancia (con el niño o adolescente como protagonista), a las enfermedades

Javier González de Dios: javier.gonzalezdedios@gmail.com

El autor declara no presentar conflictos de intereses en relación con la preparación y publicación de este artículo . 
pediátricas y/o a la realidad vista a través de la inocencia de la mirada de un niño contiene elementos culturales y docentes asociados al entretenimiento. Porque el "séptimo arte", al igual que los seis anteriores, componen un mosaico de posibilidades que los educadores utilizan para ayudar a una formación médica más completa. Literatura y teatro ${ }^{1,2}$, poesía ${ }^{3}$, ópera ${ }^{4}$ y cine $e^{5-11}$ se convierten en un recurso útil en el universo de la educación médica.

El cine, con su imagen y sonido, es un despertador de emociones dentro de la "cultura del espectáculo". El cine es posiblemente la manifestación artística más completa a la hora de plasmar una enfermedad (se ve, se oye y se siente). En los últimos años la docencia está siendo sacudida por una imperiosa necesidad de adaptación y evolución. En este sentido, las técnicas audiovisuales (entre ellas, y principalmente, el cine en sus distintos formatos), con su incomparable capacidad de representación, constituyen uno de los métodos más poderosos de difusión de conocimientos, de desarrollo de aptitudes y de creación de actitudes ${ }^{12}$.

Los profesionales de la salud han comenzado a investigar qué pacientes y enfermedades trata el cine y cómo las trata, pero sobre todo ha servido como foro de aprendizaje. Pues el cine (y también el vídeo y la televisión) es un medio de gran impacto para informar, divulgar mensajes y formar a la población. La utilización del cine como recurso educativo en estos tiempos dominados por la imagen, es una posibilidad efectiva. Si a esto se suma el hecho de que la enfermedad ha sido siempre un referente permanente de los cineastas, con muchas películas que pueden servir de base educativa, el cine se convierte en un método ideal para mostrar una mirada holística de la salud y la enfermedad. Además, los cineastas nunca se han ocupado de enfermedades, sino siempre de enfermos, de su vida, de su lucha por sobrevivir, de sus circunstancias personales y con una mirada humanitaria e integral, que los médicos podemos utilizar para una labor educativa ${ }^{13}$.

La educación encuentra en la estética -artes y humanidades- un aliado imprescindible. Educar desde la estética no es querer anclar en la emoción y en la sensibilidad todo el cuerpo de conceptos necesarios para construir los valores de la persona. Lo que se pretende es provocar la reflexión, condición imprescindible para cualquier intento de construcción de la personalidad.

El objetivo de este artículo es fomentar un espacio de reflexión sobre las 
posibilidades que el cine permite para la docencia y humanización en medicina, en general, y en la Pediatría, en particular.

\section{Un poco de historia: arte e industria conviven en el cinematógrafo}

En sus albores y por un tiempo, el cine fue considerado una atracción menor, incluso un número de feria. Una figura fascinante cambió este concepto: George Méliès desarrolló los efectos especiales para simular experiencias mágicas. Este hecho y el nacimiento en la primera década del siglo $\mathrm{XX}$ de múltiples pequeños estudios cinematográficos, tanto en Estados Unidos como en Europa, cambiaron el ritmo (ya imparable) del cine en nuestra sociedad y en nuestra vida.

Uno de estos estudios se convirtió en La Meca del cine: Hollywood, un pequeño poblado en las proximidades de Los Ángeles. La mayor parte de los estudios fundados en aquella temprana época (Fox, Universal, Paramount, Metro-Goldwyn-Mayer) miraban al cine más como un negocio que como un arte, controlando la producción fílmica, la distribución y su cartera de directores y actores (lo que marcó la aparición del star-system). Era el dominio de los magnates, nombres emblemáticos co- mo Darryl F. Zanuck, Samuel Bronston y Samuel Goldwyn. Sólo Charles Chaplin, Douglas Fairbanks y Mary Pickford se rebelaron contra esto, intentando concebir el cine más como un arte, y lo intentaron por medio de su estudio: United Artists.

La convivencia en el cine de arte e industria fue, es y será siempre una constante. Pero el desarrollo del discurso fílmico cinematográfico siguió sus pasos, precedido por los antecedentes comentados del discurso de los Lumiére (más documentalista) o del discurso de Méliès (más carnavalesco). Para entender esta evolución, no podemos dejar de enumerar tres elementos que podemos considerar clave en ese desarrollo inicial del nuevo lenguaje cinematográfico:

- En Estados Unidos, David W. Griffith y su "montaje invisible", con la implantación inicial de recursos tales como el primer plano o el flashback. El nacimiento de una nación (1915) o Intolerancia (1916) cambiaron el cine para siempre, hasta el punto de que se afirma que con Griffith nace de verdad el lenguaje cinematográfico.

- En la Unión Soviética, Sergéi Eisenstein y su "montaje de atracciones", que busca mezclar imágenes chocantes para provocar 
una asociación emocional o intelectual en el público. Lo avalan los 1.290 planos de El acorazado Potemkin (1925), posiblemente la película sobre la que más se ha escrito en toda la historia del cine.

- En Europa varios movimientos culturales se trasladan al cine, principalmente el Expresionismo del cine alemán (en el que prima la expresión subjetiva sobre la representación objetiva de la realidad) y el Surrealismo del cine francés (en el que prima la búsqueda de sensaciones y de sentimientos, imágenes absurdas que rompen con la lógica temporal). El gabinete del doctor Caligari (Robert Wiene, 1920), Nosferatu, el vampiro (Friedrich Wilhelm Murnau, 1922) y Metrópolis (Fritz Lang, 1927) son claros ejemplos del primero. Retorno a la razón (Man Ray, 1923), Entreacto (René Clair, 1924), El perro andaluz (Luis Buñuel, 1929) y La edad de oro (Luis Buñuel, 1930) son ejemplos del segundo.

Así pues, y desde sus orígenes, el cine ha evolucionado por medio de sucesivas corrientes cinematográficas, corrientes no ajenas a la evolución de otras manifestaciones artísticas o litera- rias. Paradigmas filmicos que se yuxtaponen o contraponen y que se iniciaron con las llamadas vanguardias históricas a principios del siglo $X X$, que se destacaban por la renovación radical en la forma y el contenido, explorando la relación entre arte y vida. En el cine se diferencian tres etapas en el movimiento vanguardista (impresionismo, expresionismo y surrealismo), pues otros movimientos de vanguardia (fauvismo, cubismo, futurismo, dadaísmo, etc.) no tuvieron reflejo en la pantalla. A partir de este momento, otras corrientes cinematográficas fueron apareciendo con el tiempo y dejando su impronta:

- En los años 20, el Cine-Ojo ruso (Dziga Vertov) o el Cinema-Pur francés (Henri Chomette, Man Ray Rene Clair...).

- En los años 40, el Neorrealismo italiano (Roberto Rossellini, Vittorio de Sica, Luchino Visconti...) o el Underground estadounidense (Maya Deren, Keneth Anger...).

- En los años 50, el Cinema Verité (Jean-Luc Godard, Michel Brault, John Cassavete,...), la Nouvelle Vague francesa (François Truffaut, Alain Resnais, Éric Rohmer, Claude Chabrol...), el Free Cinema británico (Lack Clayton, Lindsay Anderson, Karel Reisz, Tony Richard- 
son...) o la Vanguardia estadounidense (Stanley Kramer, Otto Preminger, Delbert Mann...).

- En los años 60, el Cine Moderno o New Hollywood (Robert Altman, Francis Ford Coppola, Martin Scorsese, Roman Polanski, Steven Spielberg...) o el Cine independiente americano (Dennis Hopper, John Schlesinger...).

- En los años 70, el Baxploitation estadounidense (Mario Van Peebles, Ossie Davis, Gordon Parks...) o el Nuevo Cine alemán (Volker Schlöndorff, Rainer Werner Fassbinder, Werner Herzog, Win Wenders...).

- En los años 80, el Cine Postmoderno (Quentin Tarantino, Baz Luhrman, Pedro Almodovar...) o el New Queer Cinema (Gregg Araki, Gus Van Sant, Todd Haynes...).

- En los años 90, el Cine Digital (George Lucas, James Cameron, hermanos Wachowski...) o el movimiento Dogma (Lars von Trier, Thomas Vinterberg, Soren KraghJacobsen...).

Las corrientes cinematográficas se solapan con los géneros. Géneros cinematográficos que se clasifican según los elementos comunes de las películas que abarquen y, sobre todo, por el sentimiento que busquen provocar en el espectador. En un intento de clasificación, de los múltiples géneros que han ido apareciendo, podemos diferenciarlos por su estilo (acción, animación, aventura, comedia, documental, drama, épico, fantasía, misterio, negro, romántico, suspense, terror, etc.) o por su ambientación (bélico, ciencia ficción, deportivo, fantástico, gore, histórico, independiente, musical, negro, oeste, policíaco, etc).

\section{Cine y medicina: recurso docente para la humanización y mejora de la relación médico-paciente}

No existe un género de cine dedicado a la medicina. Pero la medicina sí es un tema recurrente en el cine, enfocado desde múltiples puntos de vis$\mathrm{ta}, \mathrm{y}$ visible en todas las corrientes y géneros enumerados. $Y$ distintos autores han publicado comentarios respecto a esta asociación. Hay recursos que vienen compartiendo este doble interés, en busca de la conexión entre el cine y la medicina y en sus diversas facetas: información, formación, docencia, etc. En España queremos destacar algunos recursos que vienen compartiendo este doble interés entre cine y medicina: 
- La Revista de Medicina y Cinel Journal of Medicine and Movies, posiblemente la única revista que reúne estas dos materias de análisis. Es una revista bilingüe (español e inglés), electrónica y de acceso libre, publicada por Ediciones Universidad de Salamanca y cuya dirección corre a cargo de los hermanos José Elías y Enrique García Sánchez, que comparten su trabajo en el Departamento de Medicina Preventiva, Salud Pública y Microbiología Médica de la Universidad de Salamanca y su enorme afición al cine. Se publica cada trimestre desde el año 2005 y ha marcado un antes y un después en este campo. Se pueden descargar los distintos números de la revista desde la web http://campus. usal. es/ revistamedicinacine/. De lectura recomendable.

- La página electrónica "Una filmoteca peculiar" (www.fisterra.com /human/3arte/cine.asp), confeccionada por la Dra. Carolina BoteIla, médico de familia de Santa Cruz de Tenerife, cuyo contenido está colgado en la web de Fisterra.

- El blog "Medycine" (http://medi cinaycine.blogspot.com/), que se publica desde el año 2007 por el Dr. Albeiros desde Orense y que ofrece una particular interpretación cinematográfica sobre la salud y la enfermedad.

- A estos recursos nos sumamos recientemente con la sección "Cine y Pediatría" publicada dentro del blog "Pediatría basada en pruebas" (www.pediatriabasadaenpruebas. com/). Desde esta sección planteamos una selección de aquellas películas cuyos protagonistas son, de alguna manera, niños o adolescentes, algunos enfermos y la mayoría sanos. Nos vale la mirada de un niño a través de la cámara como hilo argumental para plantear diferentes problemáticas que ocurren alrededor del cuidado y atención del cuerpo, la mente, el corazón y el alma de la infancia y adolescencia.

El valor añadido de estos recursos es señalar la potencial utilidad del cine en la docencia y formación humanística y ética del médico. Una afición que puede ser más que un entretenimiento, pues el cine puede transmitir conocimientos, vivencias, experiencias... y despertar sentimientos en el espectador, quien a su vez interpreta la narración desde sus experiencias previas, al tiempo que se siente afectado por ella y la incorpora a su vida como una experiencia más propia ${ }^{14}$. 
La formación humanística y ética del médico, en general, y del pediatra, en particular, es una necesidad indiscutible. Pero los estudiantes y los jóvenes médicos (y los no tan jóvenes) presentan una curiosa convivencia entre abundantes conocimientos técnicos y escasa formación humanística. En la mayoría de las facultades de medicina los estudiantes han sido formados en enfermedades, no en enfermos. No parece que el examen MIR y la formación MIR contribuyan a mejorar sustancialmente este aspecto. Aún hoy no es infrecuente que algunos médicos no contemplen a sus pacientes como una persona (con sentimientos, con familia, con proyecto de vida particular), sino más bien como un conjunto de órganos y patologías ${ }^{15}$.

La educación de la afectividad a través del cine es un método utilizado hace más de 9 años por la Sociedad Brasileña de Medicina de Familia (Sobram$\mathrm{fa}$, que viene desarrollando "una enseñanza médica de cine", es decir, una metodología cinematográfica para ayudar a los médicos y a los estudiantes de medicina en el entendimiento más íntimo del ser humano gracias al visionado de pequeños vídeos -de menos de dos minutos- con un alto contenido emocional, ya sea por la actitud de los intérpretes, por las frases que dicen, o por las acciones que se presentan. La metodología educativa utilizada incluye: proyección de escenas breves, acompañada de los comentarios del profesor-facilitador y el debate conjunto en formato taller durante 20-30 minutos (con discusión abierta e informal para intercambio de opiniones, reflexiones o emociones que la proyección les ha sugerido) ${ }^{16}$. Nos adentra en un campo de gran interés: el cine como herramienta en la enseñanza de la medicina, especialmente para conocer la condición humana y mejorar la relación médico-paciente. Es necesario potenciar una educación sentimental, educar los sentimientos, educar la afectividad.

Se trata de establecer un punto de partida desde la que se pueda despegar para un aprendizaje más profundo. Es evidente que este proceso requiere tacto, habilidad y promover un aprendizaje que respete el ritmo de la emotividad. La cultura de la emoción está intrínsecamente unida a otro elemento integrante del universo del estudiante: la imagen o la "cultura del espectáculo". Con la imagen todo es directo, rápido, como un atajo que despierta la emoción ${ }^{17}$. El cine provoca emociones $y$, sobre todo, ofrece la posibilidad de contemplarlas y compartirlas en discusión abierta, abriendo caminos para una verdadera reconstrucción afectiva. La convi- 
vencia virtual del cine amplía las oportunidades y experiencias, provoca otras vivencias desde la pantalla. A través de las narraciones (reales o ficticias) se reflejan en las películas sus propios conflictos $y$, a través de estas vivencias virtuales, se provoca una actitud reflexiva que fácilmente se guarda en el ámbito de la memoria afectiva.

Se ha confirmado por la experiencia que el cine es un recurso educativo de alto impacto, si bien requiere cautela y conocimiento para su buen uso. Se precisa buena preparación, con objetivos concretos, experiencia en el manejo de grupos de discusión y habilidades técnicas al emplear los medios audiovisuales. Desde la experiencia de los hermanos García Sánchez, del Departamento de Medicina Preventiva, Salud Pública y Microbiología Médica de la Facultad de Medicina de la Universidad de Salamanca, y desde la creación de la Revista de Medicina y Cine, se han prodigado las experiencias docentes utilizando como herramienta el cine. Desde distintas universidades han publicado sus experiencias: Universidad Pompeu Fabra ${ }^{15,18,19}$, Santiago de Compostela ${ }^{20}$, Buenos Aires $^{13,14}$ o Salamanca ${ }^{12,21}$. El diseño docente propuesto por la Universidad de Salamanca se expone en la tabla 1.

Tabla 1. Metodología docente a través del cine propuesta por la Universidad de Salamanca

1. Selección de la película: criterios de selección:

- Sólo películas de ficción, no documentales.

- Disponibilidad de películas, a ser posibles en versión original (con subtítulos).

- Calidad cinematográfica mínima e imprescindible.

- Selección de películas atractivas.

2. Relación cinta/tema: en algunos casos el tema elegido constituye el núcleo central de la película; en la gran mayoría posiblemente sólo incluiremos apartados concretos de la misma, centrando el interés en alguna escena en particular.

3. Métodos de proyección:

- Íntegra y colectiva: la forma habitual de ver el cine.

- Proyección de secuencias elegidas en función del contenido.

- Visualización individual de una película: cada alumno puede visionarla con apoyo informático y no necesariamente implica aislamiento, pues se puede comentar posteriormente en conjunto.

4. Momento de la proyección en relación con la lección o tema teórico a tratar:

- Proyección inicial: actuaría como elemento motivador.

- Proyección final: actuaría como colofón, como elemento globalizador y que ejerce una función fijadora de contenidos.

- Proyección intermedia: quizás la más conveniente, ya que el alumno ha adquirido el marco referencial mínimo inicial y la explicación final aglutina todos los conocimientos.

5. Evaluación: el más apropiado es el método de evaluación continuada de la interacción de cada alumno con el profesor. 
Algunas películas aconsejables para iniciar un debate sobre la humanización de la práctica médica y mejora de la relación médico-paciente

Cada lector tendrá en su mente alguna película que bien pudiera incluirse en este apartado. Películas que marcan y que no se olvidan. Películas con interesantes mensajes hacia los profesionales sanitarios. Expongo una breve relación de 5 películas de aconsejable visionado, propicias para iniciarse en las potencialidades docentes orientadas a mejorar la humanización y la relación médico-paciente.
- El Doctor (Randa Haines, 1991): Jack Mackee es un brillante cirujano, rico y con éxito, convencido de la necesidad de distanciarse emocionalmente de los pacientes. Su vida cambia cuando un día unas molestias en la garganta le llevan a la consulta de una compañera, quien le diagnostica un tumor canceroso. Jack será quien padezca ahora, como cualquiera de sus enfermos, las desagradables consecuencias de la burocracia y la frialdad de los médicos que él tanto defendía... Escenas espe-

Figura 1. El Doctor (Randa Haines, 1991).

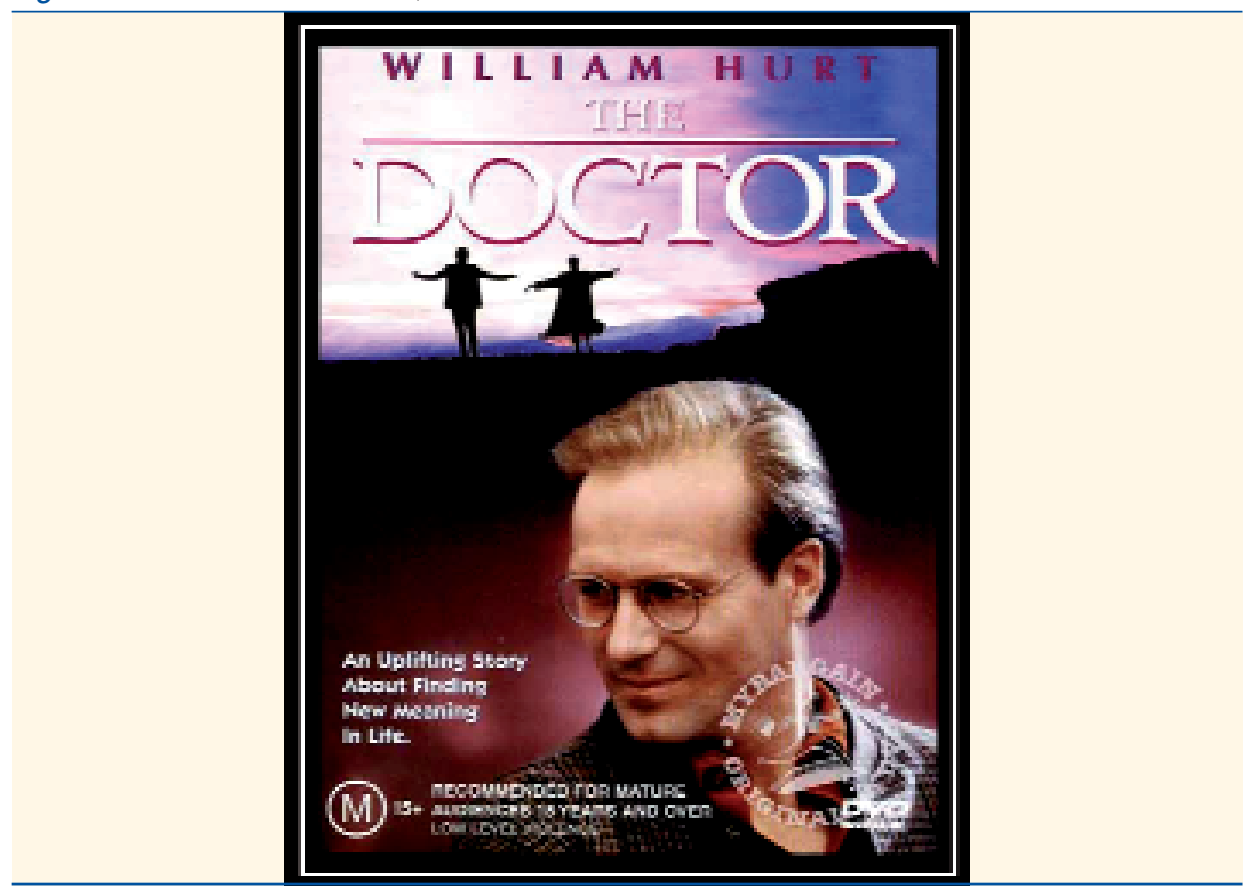


cialmente reveladoras al final de la película, cuando tras las experiencias vividas durante su enfermedad (y como enfermo), recibe a sus nuevos residentes y les obliga a convertirse en pacientes durante un día completo: visten la misma indumentaria que los pacientes, siguen la misma dieta y son sometidos a algunos de sus procedimientos diagnósticos. El último mensaje del Dr. Mackee es reconocer que los pacientes se sienten asustados, avergonzados y vulnerables y confían tanto que, en realidad, ponen su vida en las manos de sus médicos (figura 1).

- Las confesiones del Dr. Sachs (Michel Deville, 1999): una serie ágil de viñetas sobre la actividad y vivencias de un joven médico en un pueblo de Francia, con una estructura episódica y de índole descriptiva. Es ésta una película sobre la ética y sobre la función social, casi religiosa, que cumple Sachs como arquetipo. La película tiene momentos excelentes, de profunda humanidad, testimonios de la empatía entre médico y pacientes.

Figura 2. Las confesiones del Dr. Sachs (Michel Deville, 1999).

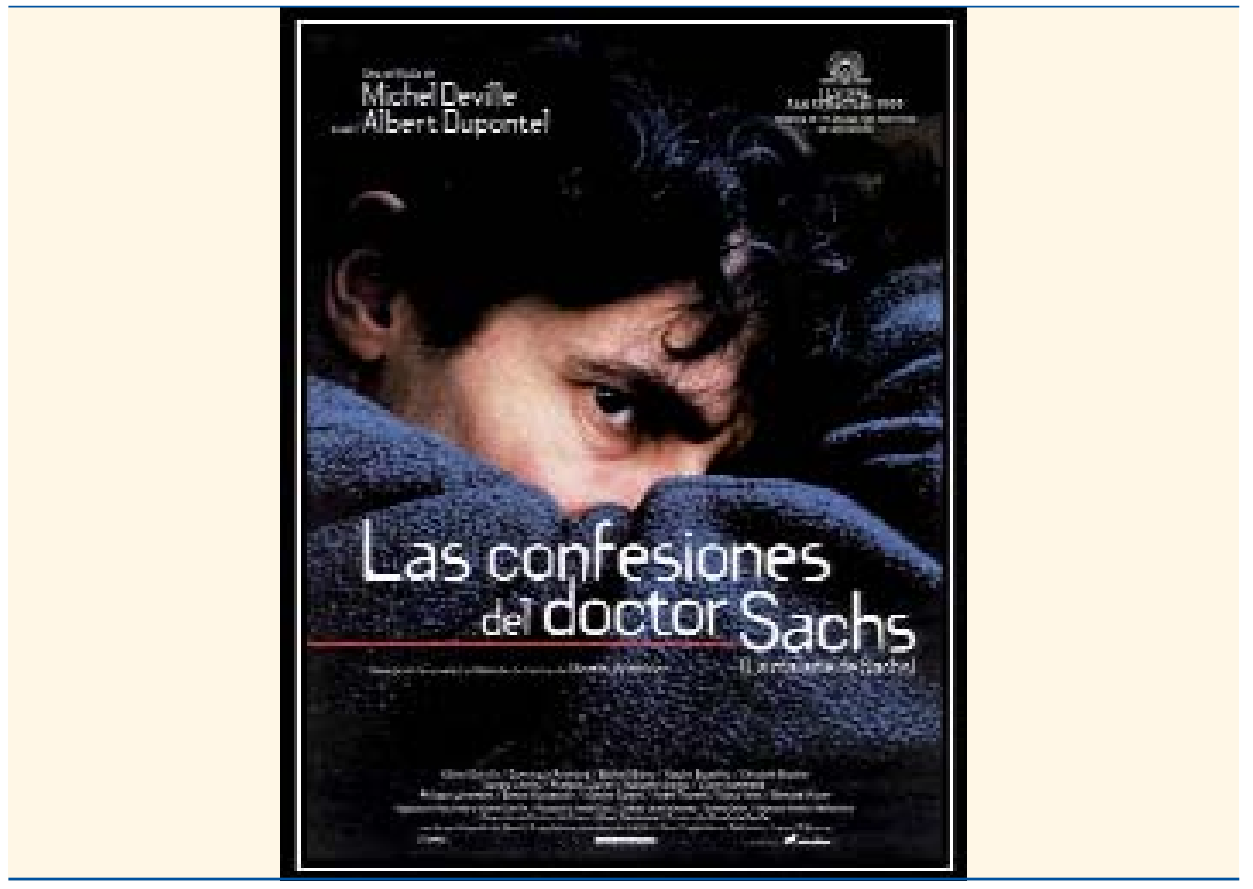


$Y$ en el que vislumbramos en muchos casos el concepto de las "consultas sagradas", consultas que no sólo mejoran para siempre la relación médico-paciente y obtienen un impacto en salud, sino que compensan al médico del diario apresuramiento tormentoso (figura 2).

- Amar la vida (Mike Nichols, 2001): una profesora de literatura, soltera y racional, a la que un día diagnostican un cáncer terminal de ovario. La película está repleta de monólogos, propios de la adaptación de la obra teatral de la que procede, de extraordinario valor. Monólogos para la reflexión, en los que no faltan los comentarios a los profesionales sanitarios $y$ en el que la enfermería queda mejor parada que los médicos. Escenas para recordar (y que todo sanitario debería ver, al menos para sentir lo que no se debe hacer) son el momento en el que se le comunica el diagnóstico del cáncer o los pases de visitas médicos (figura 3).

- Las alas de la vida (Antoni P. Canet, 2006): película documental

Figura 3. Amar la vida (Mike Nichols, 2001).

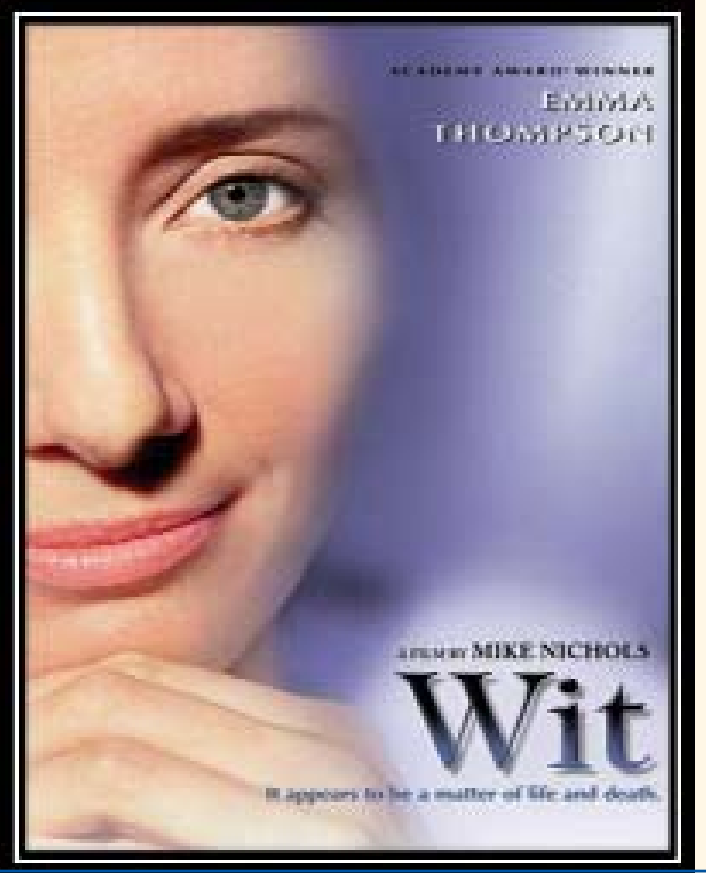


sobre Carlos Cristos, médico de familia afecto de ASM (atrofia sistémica múltiple), enfermedad degenerativa, invalidante y mortal. Auténtico cinema verité, documental filmado del 2003 al 2006, que es una reflexión en primera persona sobre la vida y la muerte, sobre la muerte digna y cómo mirarla a la cara. Reflexiones desde la perspectiva de dos médicos, Carlos y su mujer, Carmen Font, residentes en Mallorca junto a su hija pequeña. Carlos es una persona multifacéti$\mathrm{Ca}$, pero que un día en lugar de dar un diagnóstico, lo recibió y era él el que escuchaba el diagnóstico de ASM. Película muy recomendable para todos, quizás especialmente para los médicos, y que contó con la aparición de figuras de la medicina como Carlos Simó (investigador del IVI) o José María López Piñero (catedrático de Historia de la Ciencia). Película elogiada por público y crítica. Cuenta con una web propia: www.lasalasdelavida. com/index.html (figura 4).

- El mal ajeno (Oskar Santos, 2009): Diego, un médico de cuidados pa-

Figura 4. Las alas de la vida (Antoni P. Canet, 2006).

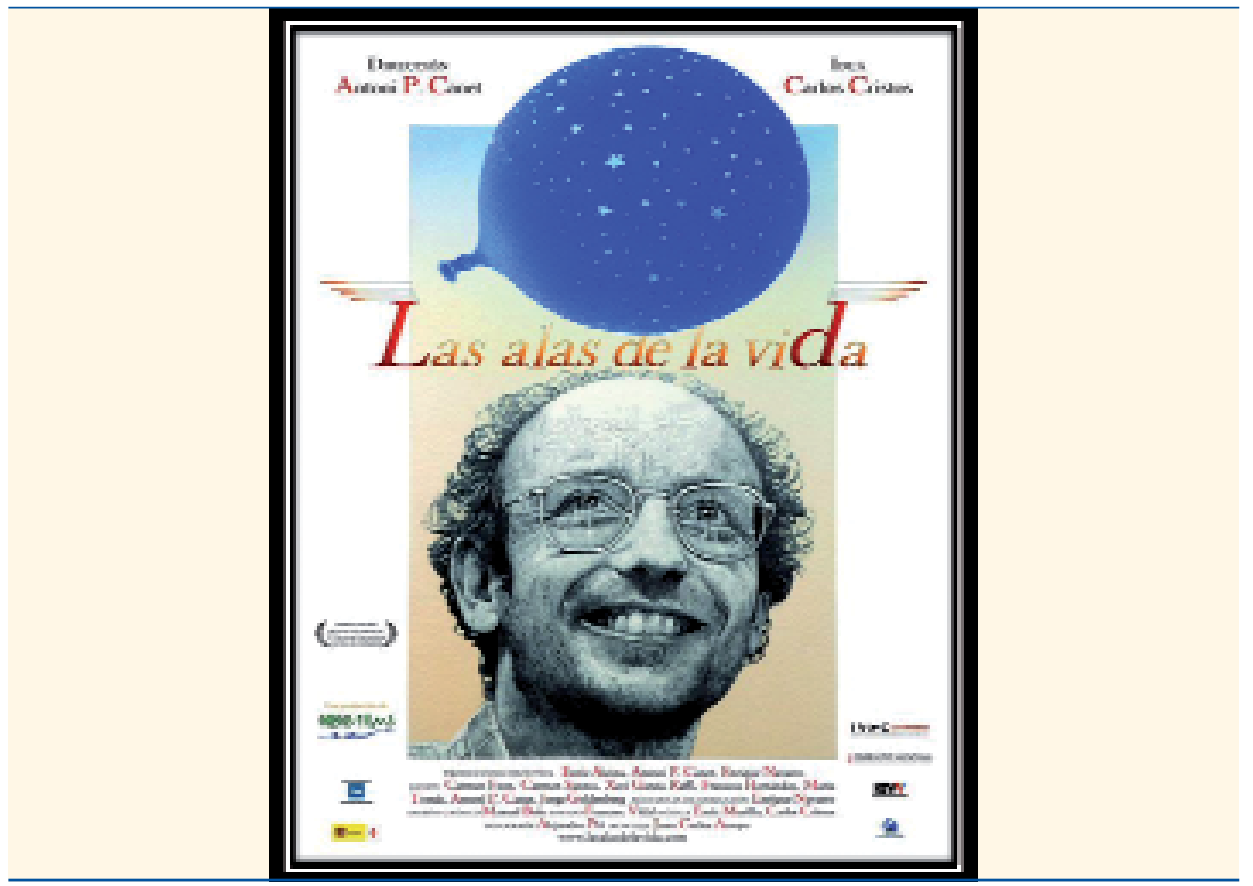


liativos, está tan acostumbrado a manejar situaciones límite que ha logrado inmunizarse ante el dolor de los demás: desconectado de su trabajo, de su pareja y de su compromiso como padre. De vuelta de todo y sin empatía con sus enfermos terminales. Todo cambia cuando le disparan, pero salva milagrosamente la vida. Posteriormente, la historia relacionará a médicos y pacientes y se verá agitado entre la milagrosa curación que empieza a sucederle a sus pacientes y los problemas de salud de su familia. Aun- que la película presenta inconsistencias melodramáticas, cabe aprovechar el planteamiento sobre los cambios de sentimientos que presenta el médico (figura 5).

No sólo el cine panorámico es una oportunidad para mejorar la enseñanza y la humanización en medicina, también las series de televisión sobre temas médicos: Anatomía de Grey, Urgencias, Hospital Central, Scrubs... hasta House (porque también de los errores se aprende...). Cualquier iniciativa artística aplicada a la humanización de la medicina debe ser bienvenida.

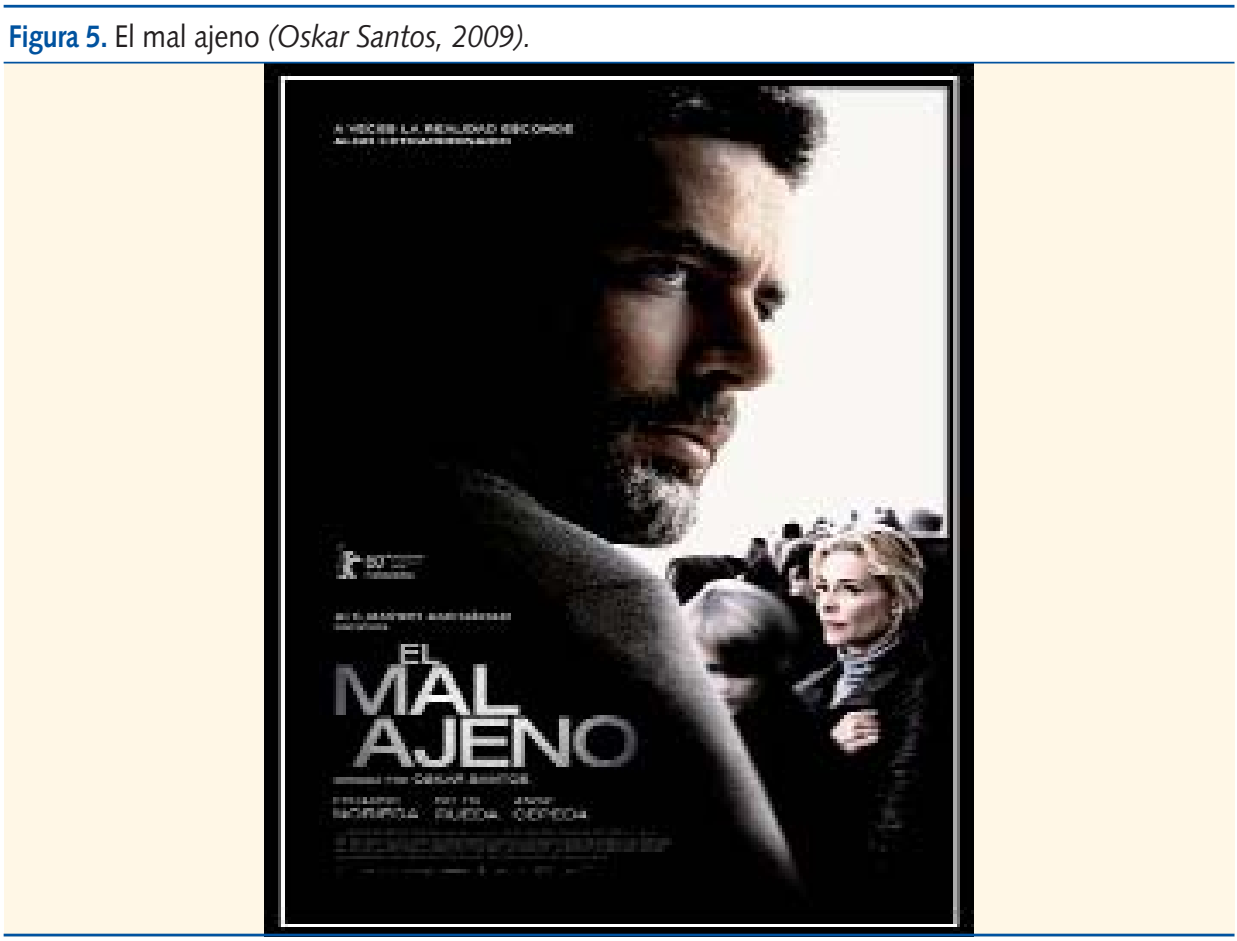


Tampoco hacemos referencia a ninguna película directamente relacionada con la pediatría. A ellas dedicaremos un mayor recorrido en la parte II de este artículo sobre cine y pediatría.

\section{Bibliografía}

1. Shapiro J. Literature and the arts in medical education. Fam Med. 2000;32:157-8.

2. Blasco PG. Literature and movies for medical students. Fam Med. 2001;33:426-8.

3. Whitman N. A poet confronts his own mortality: what a poet can teach medical students and teacher. Fam Med. 2000;32:673-4.

4. Blasco PG, Moreto G, Levites MR. Teaching Humanities through Opera: leading medical students to reflective attitudes. Fam Med. 2005; 37:18-20.

5. Ber R, Alroy G. Twenty years of experience using trigger films as teaching tools. Acad Med. 2001;76:656-8.

6. Rabinowitz D, Melzer-Geva M, Ber R. Teaching the cultural dimensions of the patient-physician relationship: a novel approach using didactic trigger films. Med Teach. 2002;24:181-5.

7. Self DJ, Baldwin DC. Teaching medical humanities through film discussions. J Med Humanit. 1990;11:23-9.

8. Seld DJ, Baldwin DC, Olivarez M. Teaching medical ethics to first-year students by using film discussion to develop their moral reasoning. Acad Med. 1993;68:383-5.

9. Wilt DI, Evans GW, Muenchen R, Guegold $G$. Teaching with entertainment films: an empathetic focus. J Psycosoc Nurs Ment Health Serv. 1995;33:6-15.

10. García Sánchez JR, Fresnadillo MU, García Sánchez E. El cine en la docencia de las enferme- dades infecciosas y la microbiología clínica. Enferm Infecc Microbiol Clin. 2002;20:403-6.

11. González Blasco P, Roncoletta AFT, Moreto $G$, Levites MR, Janaudis MA. Medicina de familia y cine: un recurso humanístico para educar la afectividad. Aten Primaria. 2005;36:566-72.

12. Fresnadillo Martínez MJ, Diego Amado C, García Sánchez E, García Sánchez JE. Metodología docente para la utilización del cine en la enseñanza de la microbiología médica y las enfermedades infecciosa. Rev Med Cine. 2005; 1:17-23.

13. Moratal Ibáñez LM. El cine y su mirada holística y humanitaria de las enfermedades. Rev Med Cine. 2007;3:85-6.

14. Cappelletti GL, Sabelli MJG, Tenutto MA. ¿Se puede enseñar mejor? Acerca de la relación entre el cine y la enseñanza. Rev Med Cine. 2007;3:87-91.

15. Baños Díez JE. ¿Cuál debe ser el grosor del estudio? La enseñanza de las sutilezas de la relación médico-paciente mediante obras literarias y películas comerciales. Rev Med Cine. 2007;3: 159-65.

16. Blasco PG, Moreto G, Roncoletta AFT, Levites $M R$, Janaudis MA. Using movie clips to foster learners' reflections: improving education in the affective domain. Fam Med. 2006;38:94-6.

17. González Blasco P, Pinheiro TRSP, UlloaRodríguez MF, Angulo-Calderón NM. El cine en la formación ética del médico: un recurso pedagógico que facilita el aprendizaje. Pers Bioet. 2009;13:114-27. 
18. Loscos J, Baños JE, Loscos F, De la Cámara J. Medicina, Cine y Literatura: una experiencia docente en la Universitat Autónoma de Barcelona. Rev Med Cine. 2006;2:138-42.

19. Baños Díez JE, Aramburu Beltrán JF, Sentí Clapés M. Biocinema: la experiencia de emplear películas comerciales con estudiantes de Biología. Rev Med Cine. 2005;1:42-6.
20. Muñoz-Crego A, Santos Rodríguez $Y$, Seoane Prado R. MicroDeCine: la docencia de la Microbiología Clínica en la Universidad de Santiago de Compostela mediante el cine. Rev Med Cine. 2009;5:87-91.

21. García Sánchez JE, Trujillano Martín I, García Sánchez E. Medicina y cine ¿Por qué? Rev Med Cine. 2005;1:1-2.

\section{Ver también en este número:}

González de Dios J. Cine y Pediatría (II): infancia y adolescencia en las pantallas de cine de todo el mundo. Rev Pediatr Aten Primaria. 2010;12:e21-e46. 